\title{
Research of Function Area Layout with an Improved SLP of Logistics Park
}

\author{
Tinglu Mi* \\ School of Economics and Management \\ Beijing Jiaotong University \\ Beijing, China \\ mitinglu@163.com \\ *Corresponding author
}

\author{
Xianliang Shi \\ School of Economics and Management \\ Beijing Jiaotong University \\ Beijing, China \\ xlshi@bjtu.edu.cn
}

\begin{abstract}
Function area layout of logistics parks has important influence on the effective operations of logistics parks. System layout design (SLP) is a widely used method for solving the facility layout issues, but it also has some limitations. The paper proposes an improved SLP that takes the internal and external constraints into the account of function area layout of logistics parks, having listed the process steps for the function area layout of logistics parks. Finally, a case analyzing was used to show the reasonability and validity of the proposed approach. The method can provide theoretical support and decision references for the function area layout planning of logistics parks.
\end{abstract}

Keywords- function area layout; logistics parks; improved SLP

\section{INTRODUCTION}

In recent years, the international and domestic industries upgrading, restructuring and functional reorganization make the status of the logistics industry in economic development become increasingly prominent. Many governments have built the logistics park for further development of the logistics industry through resource integration and scale effect. Now, however, the domestic theoretical research of logistics parks are mostly focused on the macro planning, few studies have looked at function area layout from micro views.

The main layout method used in the traditional research is SLP. It mostly used for other microscopic space such as factories by establishing an efficient tabu search line to determine the position of the adjacent facilities, but it does not consider the impact of internal geographical barriers and surrounding area[1]. The paper develops an improved SLP that takes the internal and external constraints into the account of function area layout of logistics parks. Different from previous relevant papers, the paper not only take the surrounding traffic conditions into consideration, but also take wind and noise that impact layout planning as constraints. Considering the relationship between them, the paper proposed process steps for the function area layout of logistics parks with constraint conditions and apply it into a realistic cases to verify the applicability and feasibility of the method.

\section{AN IMPROVED SLP}

\section{A. The basic principle of the improved SLP method}

The basic principle of the improved SLP method is The basic principle of the improved SLP method is taking road traffic, wind, water noise or other internal and external environment as constraints, and building incidence analysis associated with the functional areas so that make the conclusion more suitable for the practice. We can choose the key traffic facilities as the constraints, such as railway, port, freight stations, airports, etc., Meanwhile, we can also take wind and noise as virtualized infrastructures. Note that there is no link between these constraints.

\section{B. Process steps of the improved SLP method}

Function area layout of logistics parks are affected by internal and external constraints. The planning flow is illuminated in Fig. I.

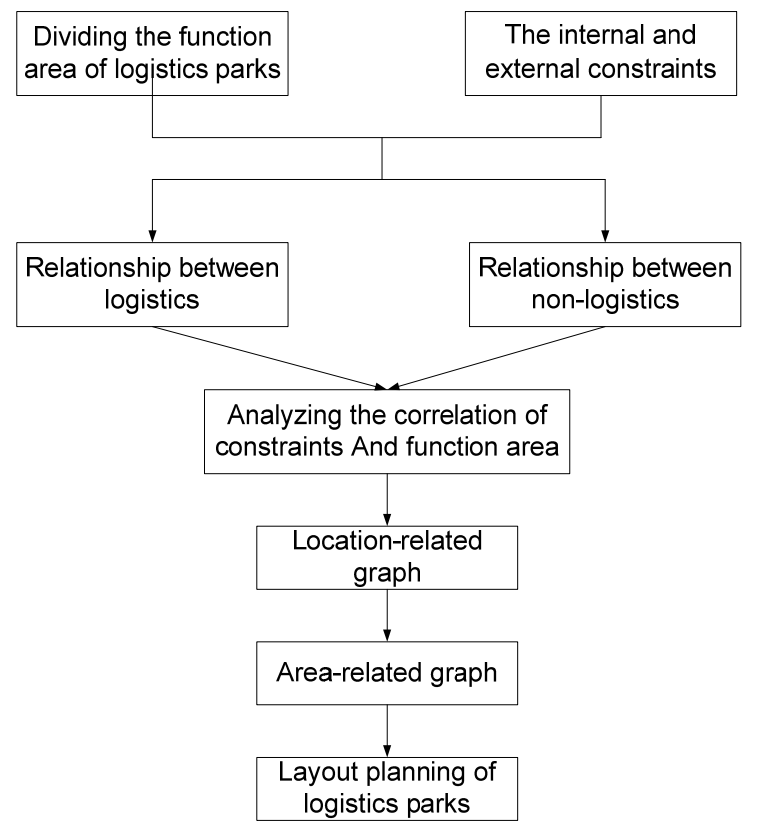

FIGURE I. PROCESS STEPS OF THE IMPROVED SLP METHOD

Specific steps are as follows:

1) Determine the constraints and functional areas: The current research of the constraints for logistics parks is to select the major transportation facilities that near the park, such as railway lines, ports, airports, highways, etc. Apart from the transportation facilities, the paper also take into account other constraints that affect functional areas layout planning, such as wind, noise, water and other factors, so that 
the final layout planning has a better agreement with the reality.

2) Build incidence analysis of the functional areas and the constraints: Consider the effect of the constraints on the layout of the function areas, notice that there is no incidence analysis among these constraints. Meanwhile analyze the correlation between logistics and non- logistics of the function areas. All things considered, we can get the comprehensive correlation analysis chart.

3) Form the area-related graph: According to the comprehensive correlation analysis chart, select the functional area which is top correlate for the constraints, and adjacent to it. Then select the function area which is top correlate for the function area that just entered the layout planning area. By that analogy, until layout has finished. Then we can get the location-related graph. Combine the function area planning area, forming the area-related graph. Finally we can put forward several plans.

4) Evaluate and select of the layout planning: Select the appropriate evaluation methods to analyze the function area layout planning of logistics parks. Consider all factors of the layout planning and determines the final planning.

\section{APPLICATION OF THE LAYOUT PLANNING}

\section{A. Introduction of logistics park}

The Zunhua logistics park located in the southeast of Zunhua that $8 \mathrm{~km}$ away from the main urban area, south of Pingdong road, west of Zhangcao railway, east of Tangzun railway, which meanders through G112. Especially, the Zhangcao railway freight stations to be built will drive the development of logistics industry. The logistics park covers 15.27 square kilometers with a comparatively large logistics park.

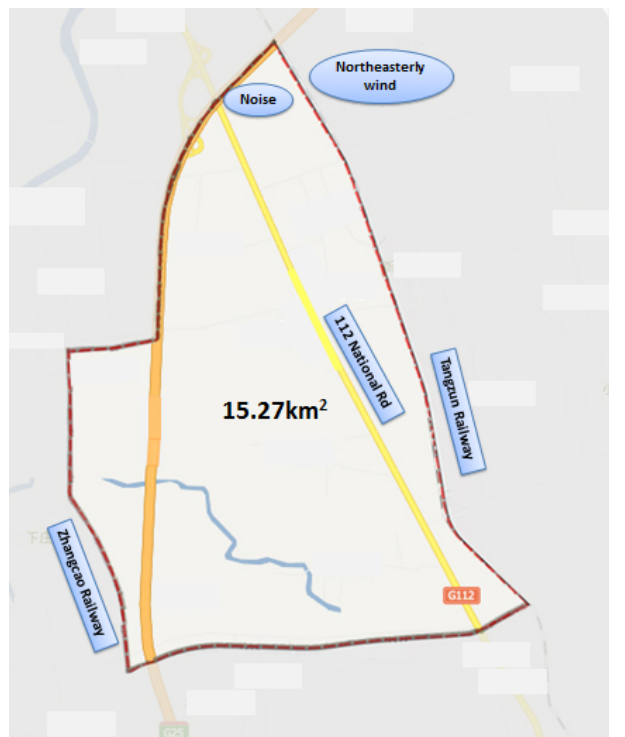

FIGURE II. THE BASIC INFO OF ZUNHUA LOGISTIC PARK

\section{B. Dividing the function area of logistics parks}

Professional business area, agriculture products area, commodity area, equipment manufacturing area, city distribution area, new industry area, international area, commercial office area and residential area are established in the Zunhua modern logistics park.

\section{Process for the function area layout of logistics parks}

1) Identify constraints: The constraints are divided into three areas: Area 1 is the road traffic, including Tangzun railway in the east, Zhangcao railway in the west and National Highway 112 that through the park. Area 2 is wind. According to statistics, the ENE winds blow over Zunhua most the year. Area 3 is noise. Around highway and rail's area usually affected by noise.

2) Analyze the correlation between constraints and function area: Consider the influence of constraints on function area layout planning and the relationship among function areas, we can get the comprehensive correlation analysis chart by calculating (see Fig.II).

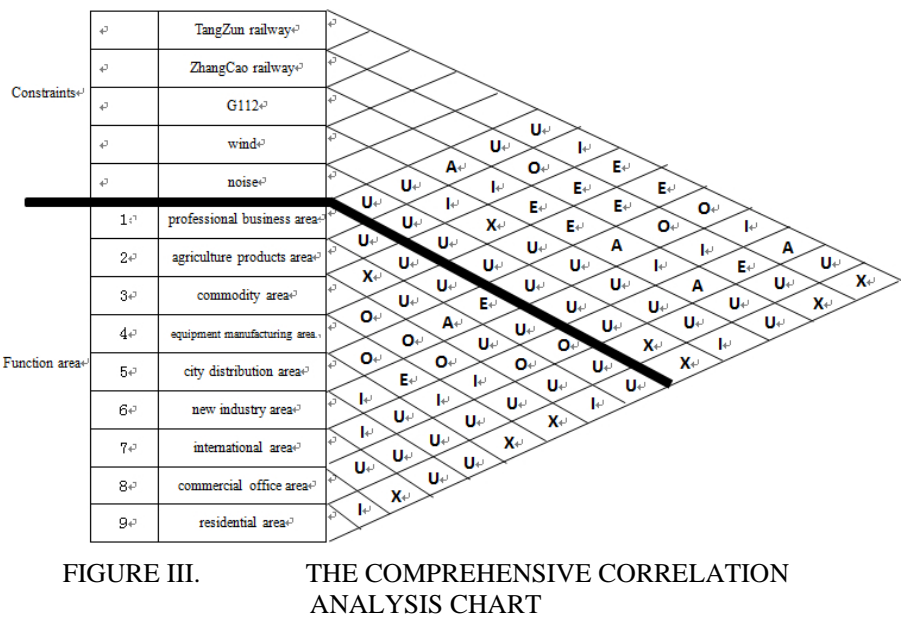

3) Determine initial plans for the function area layout of logistics park: According to calculations ,the plan area as the follows:

TABLE I. THE PLAN AREA OF EACH FUNCTION AREA

\begin{tabular}{|c|c|c|c|c|c|}
\hline No & Function area & $\begin{array}{c}\text { Plan } \\
\text { Area }\end{array}$ & No & Function Area & $\begin{array}{c}\text { Plan } \\
\text { Area }\end{array}$ \\
\hline 1 & Professional business area & 92 & 6 & New industry area & 85 \\
\hline 2 & Agriculture products area & 52 & 7 & International area & 32 \\
\hline 3 & Commodity area & 132 & 8 & Commercial office area & 50 \\
\hline 4 & Equip manufacturing area & 93 & 9 & Residential area & 20 \\
\hline 5 & City distribution area & 79 & & & \\
\hline
\end{tabular}


According to the comprehensive correlation analysis chart and the function area planning area, we finally get the two plans as bellow:
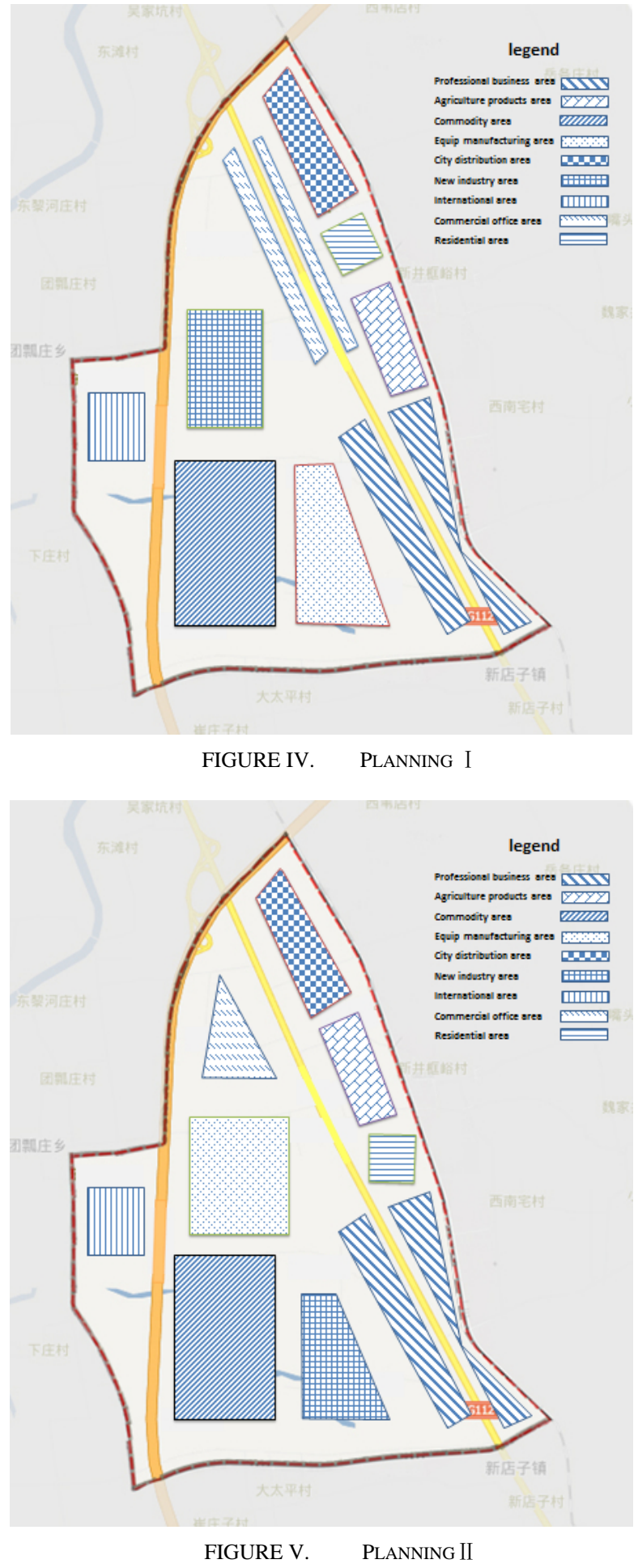

\section{The selection of candidates}

Due to the above planning is the overall planning stage results, in the plan process, most of designs were based on technical considerations and overlooked the content in the detailed planning stage. Therefore, in the stage, we set other indexes the same, we only analyzed the main technical indexes which affected the rationality of the design. Adopt the advantages and disadvantages comparison method, the main results were as follows:

TABLE II. THE ADVANTAGES AND DISADVANTAGES OF TWO PLANS

\begin{tabular}{|c|c|c|c|}
\hline No. & Evaluation Factors & Planning $I$ & Planning $I I$ \\
\hline 1 & Traffic smooth degree & good & good \\
\hline 2 & Process linkage & good & not good \\
\hline 3 & Space utilization & high & high \\
\hline 4 & Security & good & not good \\
\hline
\end{tabular}

Through comprehensive comparison of the two plans, planning 1 is the superior plan. By comparing with the function area layout planning of logistics parks of Zunhua city, we found planning 1 is consistent with the city's planning. So this method can provide theoretical guidance for the functional areas layout of the logistics park planning.

\section{CONCLUSIONS}

The paper presents an improved SLP method which taking the internal and external constraints that affect the function area layout of logistics park into consideration. The paper not only take the surrounding traffic conditions into consideration, but also take wind and noise that impact layout planning as constraints. At the end of this paper, the research result is applied to the practice. Through analyzing and calculating, the better planning is gotten. It provides actual certification for validity and reality of the model.

\section{REFERENCES}

[1] Wang Shuqin and Wei Liu,Layout planning with a controlling structure to logistics parks[A].In: IEEE International Conference on Automation and Logistics[C],2008.

[2] Zhang Changsen, Study on the Layout Planning of Logistics Park Using SLP[A.]In: 2010 3rd International Conference on Information Management, Innovation Management and Industrial Engineering[C],2010.

[3] Song Zhuoning, Research of function area layout with control structure of Nanjing international logistics[J]. Logistics Sci-Tech,2010.

[4] Yan Zhenying,Research of the relationship between the function-area layout and road traffic[D].Beijing Jiaotong University,2007.

[5] SuChao,Research of the function area layout of logistics center[D].Southwest Jiaotong University.,2010. 